\title{
Saving the Moral Capital of NGOs: Identifying One-Sided and Many-Sided Social Dilemmas in NGO Accountability
}

\author{
Stefan Hielscher, Jan Winkin, Angela Crack \& Ingo Pies
}

Abstract: The literature on nonprofit management has embraced the concept of "accountability" to target urgent challenges related to NGO probity and integrity, and the literature witnessed attempts to use rational-choice-based governance approaches to solve them. Though existing principal-agent frameworks provide important insights, they are limited to the analysis of financial relationships between NGOs and donors. We contribute to the literature in developing a comprehensive rational-choice-based governance approach to analyze all stakeholder relationships of NGOs. Applying the research program of ordonomics, we unpack two fundamental interaction problems: (a) the "stakeholder dilemma" between the NGO and a single accountability holder as a onesided social dilemma and (b) the "competition dilemma" among rival NGOs as manysided social dilemma. We show that improving NGO accountability in relation to 'intended' beneficiaries, peer organizations and the general public also requires identifying the underlying governance problem as a competition dilemma focusing on collective self-regulation as a solution.

Keywords: NGO Accountability, Social Dilemma Analysis, Advocacy, Governance, Ordonomics 


\title{
Saving the Moral Capital of NGOs:
}

\section{Distinguishing One-Sided from Many-Sided Social Dilemmas in}

\author{
NGO Accountability
}

\section{Introduction}

Non-governmental organizations (henceforth: $\mathrm{NGOs}^{1}$ ) are generally perceived by the public as trustworthy and benign actors, particularly in comparison to political institutions and the corporate sector (Edelman, 2015). Nevertheless, recent years have witnessed several NGO scandals related to corruption or the mismanagement and misappropriation of funds (Gibelman and Gelman 2001, Greenle et al. 2007). In addition, NGOs are criticized for morally controversial but legal behavior such as the misinformation or even the deception of the general public, which has resulted in increased efforts to analyze and improve the sector's reputation for probity and integrity (Hortsch 2010, Will and Pies 2016).

Many scholars in the field of non-profit management have expressed fears that the series of scandals will threaten the "moral capital"2 (Crack 2013a, p. 813) of NGOs, undermining their role as credible advocates of social causes (Ebrahim 2003). Although only a minority of NGOs seems to be involved in defamatory scandals, the moral misconduct of a single NGO may even cause substantial reputational damages for other, non-involved NGOs. Thus, even

\footnotetext{
${ }^{1}$ The term 'NGO' is notoriously broad. It can be applied to a variety of different organizational forms (Vakil, 1997). Based on a recent "comprehensive definition" by Martens (2002 p. 282), NGOs can be seen as "societal actors," i.e. as "formal (professionalized) independent societal organizations whose primary aim is to promote common goals at the national or the international level." We follow this broader definition, which also embeds Salamon and Anheier's (1992) characterization of non-profit organizations (NPOs) featuring institutionalization, independence, non-distribution constraint, self-government and voluntary participation.

${ }^{2}$ According to Kane (2001, p. 10), moral capital is "a resource that can be employed for legitimating some persons, positions and offices and for delegitimating others, for mobilizing support and for disarming opposition, for creating and exploiting political opportunities that otherwise would not exist." The "quantum" of "moral capital is when "people judge the agents or institutions to be both faithful and effective in in serving those values and goals."
} 
NGOs with the highest standards of conduct have a stake in this debate, since there is an everpresent threat that the activities of rogue NGOs could cause a crisis of public confidence that affects the credibility of the sector as a whole (Brown and Kalegaonkar 2002, Prakash and Gugerty 2010, Omona and Mukuye 2013).

NGOs and academics have developed the concept of NGO accountability ${ }^{3}$ to address these challenges (Slim 2002), using stakeholder theory as a relational approach to frame the various relationships (Brown and Moore 2001, Benjamin 2008, Cordery and Baskerville 2010, Schmitz et. al. 2012). Legal accountability matters in the case of NGOs violating national or international law (Slim 2002), and it is intended to inhibit financial misconduct such as embezzlement. Depending on the wording of the specific national law, however, legal accountability does not necessarily cover all cases of mismanagement. Such misbehavior then need to be addressed with the broader concept of moral accountability that can be invoked whenever NGO behavior conflicts with the "social values and public constituencies that it was formed to advocate and represent" (Jepson 2005, p. 520). Thus, moral accountability is a much broader, more open and thus also more contested concept to which the many academic discussions bear vital testimony (Ebrahim 2004, Lister 2003, Williams and Taylor 2013). Whenever we allude to "NGO accountability" in this paper, we refer to this broader notion of the moral accountability of NGOs.

In this article, we take the literature (Cooley and Ron 2002, Cornforth 2003, Prakash and Gugerty 2010) forward in developing a comprehensive rational-choice-based governance approach of NGO behavior by applying the research program of "ordonomics" (Pies et al. 2009, Valentinov et al. 2013). Existing principal-agent frameworks provide a sharp analysis

\footnotetext{
3 The prevailing understanding of NGO accountability is perhaps most succinctly summarized by Slim as a 'process by which an NGO holds itself openly responsible for what it believes, what it does and what it does not do in a way which shows it involving all concerned parties and actively responding to what it learns' (Slim 2002, original emphasis).
} 
of predominantly financial relationships between NGOs and donor characterized by elaborated contractual rights, including the right to demand reports and evaluation procedures (Cordery and Baskerville 2010). In addition, the donor's potential threat to withdraw funds creates a strong incentive for NGOs to meet donor standards. However, the limitations of principal-agent frameworks become evident when applied to the domain of non-financial NGO-stakeholder relations, in which potential principals possess only low sanctioning potential.

We can show that improving NGO accountability to 'intended' beneficiaries, peer organizations ${ }^{4}$ and the general public requires (a) identifying the underlying governance problem-i.e. as a one-sided "stakeholder dilemma" between the NGO and a single accountability holder — or as a many-sided "competition dilemma" among rival NGOs—, and (b) focusing on collective self-regulation as a solution (cf. XXX 2015).

We develop this argument in three steps: Following Crack's (2013a) 'two-wavesframework' we review the literature on NGO accountability in section 1, with a special focus on the rational-choice-based approaches of Prakash and Gugerty (2010) as well as Cooley and Ron (2002). In section 2, we introduce the ordonomic approach (Pies et al. 2009), briefly discuss its basic assumptions, and develop the conceptual distinction between one-sided social dilemma and many-sided social dilemma. In section 3, we apply this basic conceptual distinction to clarify the concept of NGO accountability, reconstructing two different interaction problems whose solution requires fundamentally different accountability mechanisms. In section 4, we discuss potential reform options. The paper concludes with implications for further research.

\section{Literature Review: Governance Perspectives on NGO Accountability}

\footnotetext{
4 'Peer organizations' refer to NGOs that share a broad commitment to accountability.
} 
The academic interest in NGO accountability stems from the global development of civil society within the last 25 years. After the Cold War, NGOs assumed a more prominent role in publicizing otherwise neglected social and environmental challenges in global public discourses, thus contributing to the democratic validity of governance (cf. Crack 2013b, p. 3). Yet, NGOs also attracted much criticism for mismanagement, questionable practices in fundraising, corruption and for misleading the general public, which led to calls from donors and the media for greater accountability from the non-profit sector (Cavill and Sohail 2007, p. 233; Crack 2013a).

In addition, NGOs were assuming an increasingly prominent role in criticizing the accountability of political actors and corporations (Hortsch 2010, p. 129), thereby influencing public discourse via agenda setting, but rendering themselves vulnerable to criticisms that they were not subject to the similar levels of accountability that they demanded from others (Hammer et al. 2010, p. 1). Leading NGOs began to engage in a sector-wide debate about the meaning of 'accountability' for NGOs. The establishment of major self-regulation initiatives such as the Sphere Project in 1997 and the INGO Accountability Charter in 2006 signaled that leading NGOs had reached common agreement that 'accountability' should encompass principles of transparency, participation and answerability (http://www.sphereproject.org, http://www.ingoaccountabilitycharter.org).

To review the literature on the governance dimensions of NGO accountability, we use Crack's (2013a) "two-waves" framework both to illustrate why governance reforms in NGO accountability increasingly address issues related to advocacy (Section 1.1) and how the two most advanced and comprehensive rational-choice approaches to NGO accountability fail to address related challenges (Section 1.2).

\subsection{Two Waves of NGO Accountability: Mapping Stakeholder Relationships and}


Although governance reforms vary heavily across regional and organizational factors, Crack's (2013a) "two-waves" framework helps mapping the panorama of NGO-stakeholder relationships. In doing so, we follow the broadly accepted convention to use notions of "stakeholder relations" to frame the various connections and the accountability demands between NGOs and their stakeholders (cf. also Brown and Moore 2001, Benjamin 2008, Cordery and Baskerville 2010, Schmitz et. al. 2012).

((1)) The first wave of accountability reforms amongst leading NGOs addressed "accountability for good governance". This was primarily a defensive strategy by NGOs to serve the "strategic needs to placate governments and donors to protect their autonomy from external regulation and maintain their funding base" (Crack 2013a, p. 813). Accountability was practiced using governance mechanisms such as monitoring and evaluation, which had been developed in the private sector, and have become prevalent in the public sector under the 'new public management' approach. In the first wave of NGO accountability, governance reforms focused primarily on professional management, and transparency with respect to funding and expenditure, and upward-focused (Slim 2002) relationships that were prioritized with donors (Sloan 2009, Szper and Prakash 2010, AbouAssi 2012), and political/legal authorities (Cordery and Baskerville 2010, Phillips 2012).

((2)) The second wave of accountability reforms addressed "accountability to mission" - in other words, the challenge of staying 'true' to the guiding ethos of the organization. The second wave was a reaction to what critics term the "paradox of greater NGO accountability" (O'Dwyer and Unerman 2008, 1). According to this criticism, the strategic focus of NGO accountability on powerful "upward"-stakeholders often resulted in perverse consequences, particularly in terms of further marginalizing the voices, needs and desires of intended beneficiaries (cf. also Ebrahim 2005, Murtaza 2011, Schmitz et. al. 2012, Hug and Jäger 2013). In an effort to find a remedy for this paradoxical situation, second-wave reforms 
conceived of NGO accountability responsibilities as encompassing demands and needs of a larger “downward”-focused (Kilby 2006) stakeholder environment, including 'intended beneficiaries' (cf. Saxton and Guo 2011, Schmitz et. al. 2012, Chen 2012, Williams and Taylor 2013), NGO personnel and members (Crack 2014), and "horizontally"-focused, peer organizations (Murtaza 2011). In addition to complying with 'good governance' (first wave) accountability standards, second wave governance reforms promoted organizational procedures capable of safeguarding the organization's integrity and enabling it to fulfil its mission (Cavill and Sohail 2007, p. 234). Examples include the introduction of consultation procedures with the target community and the membership, and the establishment of internal as well as external self-regulation mechanisms (Ebrahim 2003, Williams and Taylor 2013). Most importantly, strengthening accountability to second wave stakeholders is particularly challenging for the advocacy function of NGOs, both in identifying relevant second-wave stakeholders and in measuring the effectiveness of a specific advocacy activity for the relevant stakeholder group (Brown and Moore 2001).

\subsection{Rational-Choice-Based Governance Approaches to NGO Accountability}

This distinction between the two waves of NGO accountability proves a useful typology of NGO-stakeholder relationships to elucidate the strengths and weaknesses of the two rationalchoice based governance approaches to NGO accountability, which clearly stand out from the literature as the most comprehensive and elaborated perspectives.

((1)) Based on a principal-agent framework, Prakash and Gugerty $(2010,7)$ develop an "agency dilemma" to analyze the incentive problems that occur among NGOs and financial stakeholders due to asymmetric information. Originally developed as a rational-choice approach to analyze and govern the owner-manager relations in modern for-profit firms characterized by a separation of ownership and control (Jensen and Meckling 1976), Prakash and Gugerty (2010: 4) transfer the underlying analytical perspective from corporations to 
service-delivery NGOs. In other words, Prakash and Gugerty (2010) draw a direct analogy between the for-profit firm's financing problem and the non-profit NGO's funding problem. Whereas the corporate governance literature discusses appropriate governance schemes to align the manager's interests with those of the shareholders, Prakash and Gugerty (2010, p. 4) address incentive problems of NGOs and their managers to act in the interests of their donors: “[T]the principal-agent framework that we employ [...] focuses attention on the role of donors as principals and identifies appropriate governance mechanisms that are consistent with doing what the donor wants."

Prakash and Gugerty's (2010) 'club' approach is presented as a natural extension of the underlying principal-agent framework. Within the relationship between the NGO (agent) and the donor (principal), agents need a signal of credibility that they will not exploit or otherwise misappropriate the principal's support. To encourage donor support, NGOs can send a signal of credibility either individually or collectively. A voluntary regulation 'club' that provides standards for accountability, transparency and good governance, including sanctions in case of misbehavior, is seen by Prakash and Gugerty as a way for NGOs to band together collectively to send strong and credible signals to donors and governments, particularly if supplemented with strong sanctions for non-compliance.

Though clubs are functional forms of self-regulation, it is important to keep in mind that Prakash and Gugerty's (2010) clubs primarily aim at solving agency dilemmas in NGO financing and funding. In fact, it would be alien to a principal-agent framework with a focus on financial relationships to interpret any other actor than donors as principals. As a result, Prakash and Gugerty's (2010) governance approach confines its stakeholder analysis to a particular subset of actors. Other stakeholders, in particular 'intended beneficiaries' and peer organizations, are emphatically not the subjects of their principal-agent concept. Yet both the literature and NGO malpractice are testimony to the urgent need to address not only first- 
wave, but also second-wave reforms, which pose equally important challenges to NGO accountability. Though Prakash and Gugerty (2010, p. 8) underline the significance of these problems, they remain skeptical about current efforts to address these challenges effectively:

"While there has been a great deal of rhetoric about making nonprofits more "accountable" to their beneficiaries, this rhetoric is rarely matched by actual incentives or mechanisms through which beneficiaries can hold nonprofits to account. Thus beneficiaries remain clients or customers of nonprofits rather than becoming principals. Principals and beneficiaries sit at the two different ends of the value chain (or the charity chain in our context)."

((2)) Cooley and Ron's (2002) political-economy approach focuses specifically on International Organizations (IO) and on INGOs in the sectors of humanitarian aid and refugee relief as well as economic and technical assistance. Their rational-choice analysis is illustrated by three country case studies (Kyrgyzstan, Tanzania and Eastern Zaire as well as Bosnia), which highlight the competitive constraints faced by NGOs and IOs.

Similar to Prakash and Gugerty (2010), Cooley and Ron (2002) use the principal-agent framework to identify various principal-agent problems along a 'contracting chain' of donors (IOs), contractors (INGOs) and recipients (local partners), e.g. in the service delivery of development aid. Cooley and Ron (2002, p. 15) model this relationship "as a double set of 'principal-agent' problems wherein the donor is a 'principal' and contractors are 'agents.' At the lower level of the hierarchy, the contractor functions as the principal and the aid recipient as the agent." Along this relationship, Cooley and Ron (2002) analyze dysfunctional incentives for agents in short-term-contracting triggered by asymmetric information.

In contrast to Prakash and Gugerty (2010), however, Cooley and Ron (2002, p. 7) highlight that NGOs operate in a competitive environment with several NGOs competing for funding and securing contracts. Even worse, this competition is becoming more and more intense due to a growing number of NGOs and the common practice among IOs to use short-term- 
contracts for service delivery, whose compliance is then monitored by hard performance indicators. As competition increases uncertainty it also threatens to diminish the quality of service delivery within the projects, a potentially poor result that Cooley and Ron $(2002$, p. 7) interpret as a 'multiple-principals problem':

"Because alternative contractors threaten to appropriate projects, INGOs are under constant pressure to renew, extend, or win new contracts, regardless of the project's overall utility. Some INGO headquarters order their country offices to become financially self-sufficient, exacerbating the competitive dynamic. Securing new funding is an ever-expanding part of the INGO's function, pushing other concerns-such as ethics, project efficacy, or self-criticism - to the margins" (Cooley and Ron 2002, p. 16).

For Cooley and Ron (2002, p. 17), this competitive environment creates dysfunctional incentives for NGOs to "seek to undermine competitors, conceal information, and act unilaterally." If this is correct, moral behavior will be compromised by financial efforts to secure funds and short-run organizational survival, which will be to the expense of the project's performance. Yet, although even strong dysfunctional incentives leave room for deviation, ${ }^{5}$ Cooley and Ron's (2002, p. 30) case studies indicate that individual NGOs find it extremely difficult to threaten the organization's survival for the sake of moral considerations. As a result, Cooley and Ron (2002, p. 37) claim that "[w]estern donors and IOs must design humanitarian market institutions with greater care" to mitigate the negative incentives caused by dysfunctional competition. To achieve this, the authors suggest replacing the practice of short-term contracting by introducing long-term contracts.

((3)) In sum, Prakash and Gugerty’s (2010) principal-agent-framework enables a profound and sharp analysis of funding problems between donors and NGOs, including reasonable reform options. Cooley and Ron (2002) highlight that competition among NGOs is apt to aggravate the incentive problems inherent in principal-agent relations between NGOs and

\footnotetext{
${ }^{5}$ In particular, a strong moral disposition of faith-based NGO might prompt a stronger resistance in face of dysfunctional incentives. Other important considerations include the opportunity cost to cancel contracts and attract alternative sources of funding (Cooley and Ron 2002, p. 30).
} 
their donors, generating dysfunctional incentives and negative outcomes. This can lead to “mission deflection" or "mission creep" as coined by Minkoff and Powell (2006, p. 592). In addition to Minkoff and Powell's (2006) focus on mission deflection as an organizational phenomenon — caused e.g. by a strong dependence on a single donor-Cooley and Ron's (2002) analysis of competitive pressures among NGOs provides good reasons for considering also the case of a 'collective' form of mission deflection. Published more than 10 years ago, Cooley and Ron's (2002) approach retains contemporary relevance because it addresses peer organizations as important NGO stakeholders. Both frameworks focus on the funding problem of service-delivery NGOs and their accountability relationships with their principals (donors). Yet, they turn a blind eye on challenges relevant in second-wave reforms of NGO accountability, in particular those related to NGO advocacy.

The literature is rife with normative recommendations to address NGO accountability deficits to second-wave stakeholders (cf. also Ebrahim 2005, Murtaza 2011, Hug and Jäger 2013). Schmitz et al. (2012, p. 1175, italics added), for example, when considering the "decoupling of aspiration and practice," recommend that NGOs "have to be willing to share more meaningful information about their work and outcomes with stakeholders. Practicing transparency that empowers beneficiaries is central to effective organizational learning and balancing demands from different stakeholders." Yet, such normative claims appear surprisingly helpless in light of their own assessment that, in fact, NGO leaders do display very high aspirations to fulfil the needs of their stakeholders. From our point of view, such claims a fortiori underline the unchanged need for a rational-choice analysis that assumes NGOs (and their leaders) not to lack a strong will to be accountable to second-wave stakeholders, but to lack proper incentives to do so in practice (Prakash and Gugerty 2010).

Against this backdrop, we believe that NGO accountability can benefit from a conceptual perspective that addresses stakeholders such as personnel and members, intended 
beneficiaries and peer organizations with the same conceptual accuracy of a rational-choice approach as donors and funders. A comprehensive framework of NGO accountability requires an analysis of the institutional conditions of the whole panorama of NGO-stakeholder relations, including the competitive environment of NGOs, covering both the service delivery and the advocacy of NGOs. In an effort to do so, the following section presents ordonomics as research program capable of providing such a framework.

\section{The Ordonomic Rational-Choice-Approach to NGO Accountability}

"Ordonomics" represents a particular rational-choice perspective that has proven informative in the academic debates on corporate citizenship, new-governance initiatives, and tri-sectoral partnerships, because it highlights how business firms can act as governance entrepreneurs by engaging in self-regulation to create mutual benefits (cf. Pies et al. 2014; 2010). The term 'ordo' refers both to the institutional and ideational orders that structure interactions among individuals (Pies 2009). Ordonomics is a research program interested in the interdependence between institutions and ideas, i.e. how mental models and other semantic thought categories shape the rule environment for interactions-the social structure-and vice versa. A particular focus of the ordonomic approach is to take seriously both the organizational (self)interests and the larger interests of society, which allows developing reform options that create win-win-solutions, and not conflicts, among the focal organization and its stakeholders using an "orthogonal position" (Pies 2009).

Here, we apply the ordonomic research program to analyze the self-regulation efforts of NGOs (cf. Valentinov et al. 2013, 2015), and we develop a win-win semantics (ideas) that facilitates institutional or governance reforms related to NGO accountability. In particular, we show how ordonomics is useful in analyzing a broad spectrum of NGO behavior and interactions, including the issues and stakeholders relevant in 'second wave' reforms. We present the ordonomic approach of the institutional order of NGO accountability in three 
steps: First, we outline how a simple rational choice theory can be applied to analyze NGO behavior, and how it can be useful to provide counter-intuitive explanations for NGO behavior as a non-intended consequence of individually-rational behavior (2.1). Second, we distinguish two paradigmatic types of social dilemma situations (2.2). Based on this distinction, we show that one-sided and many sided social dilemmas require different types of governance reforms, namely individual and collective self-binding commitments (2.3).

\subsection{Rational-Choice Theory: A Method for Analyzing Actor Behavior}

Following Gary Becker's $(1992,37)$ strategy to use the "economic approach" for an analysis of "social issues that range beyond those usually considered by economists," rational-choice theory can be seen as an "imperialistic" method to analyze the general behavior of (human) actors. Gary Becker's notion of rationality views actors to "maximize welfare as they conceive it, whether they be selfish, altruistic, loyal, spiteful, or masochistic" (ibid.; italics in original). This idea of rationality assumes little more than actors making prudent choices, i.e. that they choose those courses of action among a variety of options (means) which best fulfill their objectives (ends). Most importantly, however, this assumption is a methodological decision (the famous "as if"-assumption) and not an ontological statement about the nature of human beings or about their 'real' thought processes, let alone a normative statement about the desirability of particular ends actors wish to achieve. This methodological openness allows rational-choice theory to be applied to a wide range of social phenomena, far beyond the narrow field of economic exchange.

"Imperialistic" rational-choice approaches are very careful in ascribing the different action parameters to the two categories of means and ends. When applied to NGOs as organizational actors, a rational-choice approach explicitly acknowledges that NGOs cultivate a selfconception as norm-driven actors and, thus, interprets the mission of NGOs as their final goal (end). To achieve this end, NGOs use financial and human resources, e.g. by generating 
member support, attracting donations and gaining public attention (means), to engage in strategies such as service delivery or cause-based campaigning or advocacy (interim ends). This understanding echoes Prakash and Gugerty's (2007, p. 1) assumption that "NGOs as collective actors ... seek to fulfill both normative concerns and instrumental incentives."

\subsection{Good Intentions, Bad Outcomes: From Moral Dilemmas to Social Dilemmas}

The rational-choice approach has often been criticized for its tautological nature, even among prominent economists. Amartya Sen (1977, p. 325), e.g., criticizes that rational behavior "is to be 'explained in terms of preferences, which are in turn defined only by behavior.' Not surprisingly, excursions into circularities have been frequent." In contrast to Sen (1977), we concur with Gary Becker's idea that a case-oriented application of this tautology demonstrates its explanatory power in providing counter-intuitive insights (Becker 1992). In fact, the rational-choice approach that follows Becker's methodology can be called "abductive," an approach which is "neither purely inductive or deductive," because it constantly searches for "the most plausible and coherent set of explanations consistent with the available data" (Heckman 2015, p. 3-4). ${ }^{6}$

Thus, instead of falling into the trap of attributing the adverse aspects of NGO behavior to the actor's bad intentions, morally controversial preferences or to pure chance, the rationalchoice approach provides a heuristic to explain how reported and stated intentional behavior can lead to empirically observable, non-intended consequences. Take the example of NGOs that played a tragic role after the infamous genocide in Rwanda 1994. Having been trapped in a moral dilemma, NGOs provided humanitarian aid to "members of the Hutu and perpetrators of the genocide" in refugee camps in the Democratic Republic of Congo. In the aftermath of the crisis, NGOs themselves feared that their "well-intentioned actions led to the prolongation

\footnotetext{
${ }^{6}$ For Heckman (2015, p. 3-4), Gary S. "Becker abducted economics," specifying that in "many of his efforts to understand economic phenomena, he brought creative insights in response to initial mismatches between models and data."
} 
of the conflict and the suffering of refugees in the camps“ (Deloffre 2010, p. 186). Instead of (only) paying lip service to their moral duties, the concerned NGOs responded with an effort to reform the incentives under which they severely suffered: They increasingly engaged in collective accountability clubs and began replacing a "truck and chuck" approach for a more holistic root-focused approach (Deloffre 2010, p. 187), which constituted a fundamental conceptual shift in humanitarian aid.

Sure, this is an extreme example, and it is not a perfect analogy to the kind of moral misconduct of NGO we described earlier. Yet, it well illustrates the structural need for a heuristic approach capable of explaining the fatal consequences of "well-intentioned actions" and developing reform options that avoids the tragic choices in moral dilemmas. Instead of giving ethically well-informed advice of how to best position within a moral dilemma, the ordonomic approach systematically translates moral dilemmas into social dilemma situations. Social dilemmas are a specific heuristic 'lense' to analyze and explain how intentional behavior can lead to non-intentional consequences. A social dilemma is a situation of collective self-damage "in which rational actors fail to realize their common interests due to conflicting individual interests" (Beckmann et al. 2014, p. 26). Yet the social dilemma 'lense' is not only a specific analytical perspective. Social dilemma situations can also be viewed from an empirical perspective as a "signum of modern societies," and observers propose different explanations for their relative occurrence: Valentinov and Chatalova (2016) invoke Luhmann's (1977) functional differentiation of modern societies in autopoietic systems to argue that social dilemmas are emergent due to the "systems' disregard of their environment," while Hielscher and Pies (2016) refer to North et al. (2009) to argue that social dilemmas result from the overwhelming significance of competition in modern society, especially in the economy, in politics, and in civil society. 
The ordonomic rational-choice approach differentiates between two archetypical forms of social dilemma situations in which the involved actors miss the opportunity to realize a winwin potential of cooperation: A one-sided social dilemma is an interaction problem characterized by the possibility of asymmetric exploitation between two actors (Kreps, 1990). Actor A can exploit actor B, but not vice versa. If B anticipates the exploitation upon his cooperation, he is "unlikely to cooperate, even though successful cooperation would be mutually advantageous" (Beckmann et al. 2014, p. 26). This situation leaves both actors worse off. Prakash and Gugerty’s (2010) "agency dilemma" of funding is a specific sub-form of a one-sided social dilemma, in which donors hold back their intended funding because they fear their support will be exploited by NGOs.

A many-sided social dilemma is a symmetric situation in which cooperation fails due to the reciprocal opportunity for mutual exploitation (Bowles 2004, p. 23-55). A famous example of such situation was described by Hardin (1968) as the "tragedy of the commons," in which all actors can mutually exploit each other. This scenario represents a situation of collective selfdamage because each actor behaves exactly the way he fears the others will, that is, exclusively in their own self-interest (Beckmann et al 2014, p. 26). The many-sided social dilemma is particularly useful for analyzing the incentive structure of "collective action problems" which arise among competing NGOs (Prakash and Gugerty 2007, p. 1). In a manysided social dilemma, the pursuit of moral ends can be contested if (only) immoral behavior is presumed to ensure a competitive advantage over other NGOs or even organizational survival. For example, a race-to-the-bottom competition for public awareness can tempt NGOs to incrementally reduce quality standards in their promotional campaigns, favoring sensationalism over sober representation of the issues. This undermines the reputation of the NGO as a trustworthy actor, and it can also endanger the credibility of the whole NGO sector if negative reputation effects "spill over" to other NGOs (Will and Pies 2016). In a similar 
way, competition among NGOs for funding can promote the adoption of management instruments imported from the private sector that shall secure a financial accountability to donors and commissioning agents. Yet, a perceived economization of NGOs or an extreme managerialism might also threaten the identity of NGOs that view and describe themselves as moral actors (Dichter 1999). Such effects join the ranks of unintended consequences of intentional behavior of NGOs.

\subsection{Infusing Order: Individual and Collective Self-Binding Commitments}

Building on Williamson's (2009; p. 456) understanding of governance as a "means by which to infuse order, thereby to mitigate conflict and realize mutual gain," it is possible to argue that overcoming the collective self-damage inherent in social dilemmas situations require appropriate governance mechanisms in the form of self-binding commitments. ${ }^{7}$

In a one-sided social dilemma, the potential exploiter A can bind herself with an individual commitment. If this commitment lends credibility to A's promise not to exploit actor $\mathrm{B}, \mathrm{B}$ will be more willing to cooperate, and both sides can reap the win-win rewards of their cooperation. In contrast, overcoming a many-sided social dilemma requires a collective commitment — an individual self-commitment is insufficient. If just one actor engaged in unconditional cooperation, the others would still have an incentive, perhaps even a stronger one, to exploit this cooperative behavior. A way to avoid this collective self-damage is through a credible collective self-commitment that changes the incentives for all actors and induces them to simultaneously change their strategies (Beckmann et al. 2014, p. 26).

Following our rational-choice-based governance approach, the term 'commitment' refers to influencing an actor's behavior by changing incentives. This term is not synonymous with

\footnotetext{
7 From a system theory perspective, Valentinov and Chatalova (2016, p. 6) argue that overcoming social dilemma situations in general calls for a "weakening of incentives." For an institutional economic perspective on how to establish a differentiated management of social dilemmas in modern society, cf. Hielscher and Pies (2016).
} 
the term 'accountability mechanism' which, according to Slim (2002), means delivering information and responsiveness to NGO stakeholders. The relationship between both terms resembles the relationship between methodology and content: A formal accountability mechanism can prescribe NGOs to disclose information or to respond to complaints, such as the INGO Charter's (2016) "Complaints Handling Mechanism." From a governance perspective, this accountability mechanism can also feature a commitment logic insofar as it helps e.g. a focal NGO to individually bind itself to the promise not to exploit a single stakeholder's prior investment.

\section{Identifying One-Sided and Many-Sided Social Dilemmas in NGO Accountability Practice}

The existing literature on NGO accountability faces difficulties addressing the second-wave accountability challenges - i.e. the problems related to accountability to mission-, because it provides little guidance for how to conceptually capture the relationships between NGOs and second-wave stakeholders, such as 'intended beneficiaries' and peer organizations. If these challenges are not adequately addressed, there is every reason to fear the erosion of the whole NGO sector's credibility and "moral capital" (Crack 2013a, p. 812), with potentially devastating effects on NGO agenda-setting and problem-solving capacities. In this section, we apply the ordonomic approach to the different NGO-stakeholder relations and analyze them as interaction problems, i.e. ((1)) as a one-sided stakeholder dilemma and ((2)) as a many-sided competition dilemma. After that, we propose ((3)) a typology of governance mechanisms for NGO accountability based on the two-wave-framework that demonstrates how one-sided stakeholder dilemmas overlap with many-sided competition dilemmas. In discussing various social dilemma situations, we are providing primarily examples of advocacy NGOs. Yet, the same logic of distinguishing one-sided and many-sided social dilemmas in NGO accountability can also be applied to service-delivery NGOs. 
((1)) One-sided social dilemmas: The first interaction problem can be interpreted as a vertical relationship between an NGO and its stakeholders such as donors, government bodies, NGO staff or intended beneficiaries. Donors provide valuable funds and demand transparency about their expenditure and evidence of performance; government bodies grant tax exemption privileges to NGOs but impose restrictions on political activities in return; personnel and members put their personal integrity at risk and demand delivery of mission; and, certainly with limits, 'intended beneficiaries' confer status to NGOs as authentic advocates of their interests, and to some extent, legitimize NGOs' activities through their cooperation (Crack 2013a, p. 813 et seq., see also table 1).

Following Pies et al.'s (2009, p. 383 et seq.) game-theoretic rational-choice framework, the interaction between NGOs and their stakeholders can be analyzed as a one-sided prisoners' dilemma (Kreps 1990), which is characterized by the possibility of asymmetric exploitation. In contrast to Prakash and Gugerty's (2010) "agency dilemma," we refer to this dilemma as a "stakeholder dilemma" to leave the door open also for stakeholders other than donors and funders (Figure 1a) ${ }^{8}$ : The stakeholder — the donor, the government, personnel, members or intended beneficiaries - can choose between the strategy to "support" and "not support" the NGO. The NGO can choose between being "accountable" and "not being accountable," i.e. the NGO can decide whether to exploit or not to exploit the support provided by the stakeholder. ${ }^{9}$ The ordinal pay-offs indicate the result of each player's individual cost-benefit

\footnotetext{
${ }^{8}$ We reconstruct the prisoner's dilemma as a 'one-shot-game', which is a special case and indeed very reductive. In fact, game theorists can show that the tendency to cooperate is much higher if games are played repetitively (Axelrod 1980). Yet, analyzing the situational logic of the underlying game helps describe the basic interaction problem under uncertainty and sheds light on the 'rules of the game' necessary to overcome the problem. Thus, our use of game theory follows Buchanan's $(1987,1990)$ constitutional economic understanding who distinguishes between 'choices among rules' and 'choices within the rules.' Accordingly, overcoming a social dilemma requires addressing the "constitutional level."

${ }^{9}$ For explanatory purposes, we use archetypical and, indeed, simplified strategy options for both players. We try to keep the game as simple and abstract as possible to emphasize its broad applicability. Of course, depending on the situation, it is possible to design a game tailored more closely to empirical situations, including more specific strategies. For example, instead of a binary strategy choice of being "accountable" or "not being accountable," a game could be reconstructed in which the NGO, e.g. Amnesty International, can choose among two action plans, one of which features "greater long-term accountability" and the other "lower long-term accountability" to intended beneficiaries. With the ordinal pay-offs unchanged, given that the first action plan faces higher
} 
analysis, with high numbers representing a high net benefit (comprising both monetary and non-monetary terms).

Figure 1 about here

Assuming rational actors, this game can be solved by backward induction. If the stakeholder provides specific support, the NGO has the potential to exploit it $(2>1)$. Yet anticipating the NGO being unaccountable, the stakeholder will decide not to support the NGO $(0>-1)$. This game leads to the equilibrium result $(0,0)$, which is suboptimal for both players. Both could profit if the stakeholder provided support and if the NGO did not exploit this support, which would result in a Pareto-superior strategy combination $(1,1)$. The actual outcome of this game is collectively self-damaging because both players would prefer $(1,1)$ over $(0,0)$. This model illustrates the importance for NGOs to avoid being trapped in dysfunctional or even disastrous incentive structures.

Figure $1 \mathrm{~b}$ assumes that the NGO employs a governance mechanism in form of a sanction $\mathrm{s}$ that is strong enough to support a credible commitment. The promise not to exploit the stakeholder's investment thus becomes trustworthy. The sanction is strong enough only if the strategy "not being accountable" loses its potential attractiveness, i.e. if the condition holds that $2-\mathrm{s} \prec 1$. As a consequence, the NGO will lose its interest in exploiting its stakeholder. Anticipating this change of incentives for the NGO, the stakeholder will go ahead with the investment. The new equilibrium $(1,1)$ is pareto-superior. Here, an individual self-binding commitment of the NGO is a win-win strategy.

investments than the latter, our simplified version of the rational-choice analysis can thus easily incorporate the time dimension as well. 
The literature on nonprofit management and public administration documents various forms of individual self-regulation aiming at governance reforms to solve "stakeholder dilemmas." With regard to first wave stakeholders such as donors and governments, Ebrahim (2003) gives account of NGOs introducing self-commitments such as the production of regular reports to donors on the expenditure of funds and project evaluations, and compliance with official procedures in order to conform to the requirements of legal accountability. Both individual self-commitments are intended to help NGOs choose the strategy "being accountable" which in turn shall ensure the support of their stakeholders, be it institutional donors or state authorities (Fig. 1). In both cases, the promises seem to be credible in practice, because the related sanctions - represented by "s" in Fig. 1b-are observed to be strong, ranging from a complete withdrawal of funds to the imposition of fines or the denial of a registered status as tax privileged NGOs (Crack 2013a).

Second wave governance mechanisms, especially their potential to effectively sanction NGOs misbehavior, prove much less effective (Prakash and Gugerty 2010, p. 8). A small number of NGOs introduced institutionalized democratic procedures and organizational bodies, including annual general meetings (AGMs) and board elections, in order to foster accountability to their members (e.g. Amnesty International, or AI). Other NGOs have attempted to formalize links with their intended beneficiaries by inviting representatives onto Advisory Boards (e.g. Save the Children). From the governance perspective of ordonomics (Pies et al. 2009, p. 389), these mechanisms can be interpreted as functional self-binding commitments and, thus, as a contribution to overcome a "stakeholder dilemma," with NGOs attempting to fulfill their mission in accordance with the expectations of members, personnel and intended beneficiaries. It is important to note that these self-binding commitments are effective both for the service delivery and the advocacy function of NGOs in their relation to second-wave stakeholders. 
Against this backdrop, waiving the funding sources of specific donors can be interpreted as an individual self-commitment of NGOs to prioritize their responsibilities to second wave accountability stakeholders. As an example, Amnesty International (2015a) states: "To ensure our independence, we do not seek or accept money from governments or political parties for our work in documenting and campaigning against human rights abuses. In no way do monies received from corporate donors influence or affect our ability to campaign." Although directly addressed, it may be inaccurate to interpret this statement as a commitment of AI toward governments and corporate donors. In contrast, our framework suggests viewing this promise as a self-commitment of Amnesty International (named "NGO" in Fig. 1) to be accountable to their members and their personnel (named "Stakeholder" in Fig. 1). By publically announcing to forestall cooptation or capture by governments and corporations, AI promises to maintain and promote organizational integrity in fulfilling its mission (Minkoff and Powell 2006, p. 595), which is an important precondition for the support and the collaboration of both members and personnel. This is a credible promise because members and personnel can easily observe the high costs of AI foregoing rich sources of external funding (sanction "s" in Fig. 1b). Viewed from the ordonomic perspective, this example also illustrates and explains that NGOs promote accountability not only for monetary reasons, e.g. for maintaining membership fees, but also for non-monetary purposes, i.e. for sustaining member support, organizational reputation, as well as fulfilling AI's mission in general. As AI has never accepted funding from governments since its foundation, this historical example also underlines that the "two-wave" framework is to be understood as an illustration for overall trends in NGO accountability, not as an analytical explanation for every single case (Crack 2013a).

Recent developments in implementing so-called "Complaints Handling Mechanisms" (CHM) of the INGO Accountability Charter (2016) provide more examples of individual self- 
commitment of NGOs. Directed primarily at NGO members and voluntary staff, CHMs are an effective tool to safeguard the support of second-wave stakeholder groups. Following the logic of self-constraining to secure mutual gains of future cooperation, the focal NGO (named "NGO" in Fig. 1) that adopts a CHM promises to give all stakeholders (named "Stakeholder" in Fig. 1) the opportunity to raise complaints related to perceived (moral) misconduct and to respond appropriately to all these complaints. As the promise to 'respond to all complaints' is easy to monitor and, thus, also to sanction for the affected stakeholders, the strategic option to ignore stakeholder complaints (i.e. 'not being accountable') becomes less attractive for the focal NGO. Although the CHM appears cost-intense from a resource-based view, the CHM's advantage is to foster the individual NGO's reputation, thereby safeguarding the support of current members and gaining potential new members, because the CHM supports organizational learning processes to strengthen the NGO's stated mission. In sum, the CHM creates a win-win situation: it 'pays off' both for the organization and for members and voluntary staff.

Yet, as in the case of the 'intended beneficiaries,' governance mechanisms such as CHM, social audits or community participation perform a much weaker effect of sanctioning perceived NGO misbehavior (Ebrahim et al. 2014). Though being a useful channel for direct feedback of intended beneficiaries, ad hoc participation remains only a vague instrument for intended beneficiaries to effectively influence NGO accountability. They do not compare to the influence consumers have to signal their disapproval with corporate decisions by changing their spending habits, or the power that voters have to hold political actors to account via the ballot box (Ronald 2010, p. 181). No doubt, these 'second wave' governance mechanisms provide much weaker incentives than those applied in NGO-donor relations.

While our conceptual approach provides a framework to capture and clarify these governance mechanisms as a contribution to solve different "stakeholder dilemmas", it faces 
similar limitations as Prakash and Gugerty's (2010) 'agency dilemma.' One reason for the decoupling of rhetoric and actual practice in NGO accountability (Schmitz et al. 2012) to intended beneficiaries is the (sometimes) weak potential of these stakeholders to effectively sanction irresponsible NGO behavior. This also seems to be one of Prakash and Gugerty`s (2010, 6-7) main concerns with amplifying the principal agent approach to a wider range of stakeholders. In many cases, dissatisfied 'intended' beneficiaries can stand up and declare publically that a certain organization did not adequately represent their interests. This can adversely affect perceptions of the integrity of the organization. However, other 'intended' beneficiaries, especially in developing countries, face much stronger difficulties to get heard by a wide audience and to build up a substantial sanction potential. For those stakeholders, "nonprofits are often the monopoly providers of essential products and services" (Prakash and Gugerty 2010, p. 5). Even more serious is the situation with primary constituencies such as 'future generations' or 'endangered species.' Notwithstanding that it would be difficult to map these groups as "stakeholders" in our framework, it cannot be ignored that they are unable to protest against NGO misrepresentation of their interests.

((2)) Many-sided social dilemmas: In many cases, staying true to mission, which is the specific focus of second wave accountability reforms, can assume the characteristics of a public good in an economic sense (Samuelson 1975). That means, if staying true to mission both in service delivery and in advocacy will not be effectively remunerated by any particular stakeholder group (or will not be effectively supported by stakeholder sanctions), NGOs may be tempted to occasionally give way to other, more 'private,' considerations, including financial incentives and donor interests. In fact, the mission drift or mission deflection so much bemoaned in second-wave accountability reforms can be seen as a type of free-riding that prevents the public good "mission fulfilment" to be effectively provided. 
A typical situation in service delivery is when multiple NGOs are bidding for a contract with a commissioning agent. NGOs willing to be commissioned may be tempted by competition to decrease the quality of service delivery, while losing sight of their mission, but maintaining the agreed amount of funds. In this case, however, the NGO's interests to staying true to its mission is directly supported by the strong interest of commissioning agents to increase the quality of service delivery, which, as a result, provide effective, sanction-based solutions (Cooley and Ron 2002). In contrast, staying true to mission is much harder to achieve for NGOs in their advocacy work. In this case, 'weak' stakeholders can lack the capability of supporting NGOs in fulfilling their mission. Then, NGOs may be tempted to campaign for funding with arguments and images that eventually gain public attention, but paint a misleading or even distorted picture of the situation of intended beneficiaries (Manzo 2008).

A potential candidate for providing sanctioning and, thus, the public good of mission fulfilment, is the general public as the primary addressee of most NGO advocacy. However, the general public consists of individual citizens who cannot be expected to solve the freeriding problem of NGOs because they may remain "rationally-ignorant" about these issues. That means, it can be very costly to inform oneself about complex societal topics and to participate in public discourse (in terms of time and other resources). If those costs are considered prohibitively high in comparison to possible benefits, the individual citizen will remain 'rationally-ignorant' against monitoring NGO service delivery and advocacy work and, thus, will not provide effective governance assistance via sanctioning (Pincione and Tesón 2006, p. 15).

Following Pies et al.’s (2009, p. 383 et seq.) game-theoretic rational-choice framework, the interaction problem of establishing and maintaining a reputation of staying 'true to mission' can be analyzed both as an individual and as a collective problem. The individual dimension 
involves reputational mechanisms in the stakeholder dilemma as described above. The collective dimension addresses issues of collective reputation of the NGO sector as a whole, thus capturing cases when the misconduct of one NGO spills over to others and creates a negative reputation for non-involved NGOs. This collective case can be analyzed as a manysided social dilemma between multiple NGOs (or the whole NGO sector), which is characterized by the possibility of symmetric exploitation among members of this sector. We refer to this horizontal interaction problem as the "competition dilemma" among NGOs that can occur in different settings, both in service delivery and advocacy.

In NGO advocacy, staying true to mission translates into responsible campaigning in light of typically rationally-ignorant citizens and a media bias that favors strident communication strategies (Swinnen 2011, Swinnen et al. 2011). Of course, 'responsible campaigning' is not (yet) a clearly-defined concept. Indicating a similar challenge, Lang (2013, p. 117-118) uses the concept of public accountability (cf. Will and Pies 2016) that entails transparency, debate, engagement and activation. In a similar fashion, Brown et al. (2012) highlight that International Advocacy NGOs addressing complex issues on multiple levels need to launch long-term campaigns to change policies that require "extensive planning, high-quality research, dedicated human resources [and] multi-year funding" (Brown et al. 2012, p. 1105). In practice, some leading INGOs have defined 'responsible advocacy' to include 'accuracy of information' as a relevant standard (INGO Charter 2016). On a national level, the Irish Association of Non-Governmental Development Organisations has implemented a sectoral voluntary Code of Conduct on Images and Messages that aims to "[a]void images and messages that potentially stereotype, sensationalise or discriminate against people, situations or places" (Dochas 2016).

Figure $2 \mathrm{a}$ serves to illustrate the underlying logic of the competition dilemma with the well-known case of the two-sided prisoners' dilemma (Pies et al. 2009), applied to the 
specific case of responsible campaigning. Two NGOs (NGO 1 and NGO 2) each have the option to engage in a populist or "irresponsible campaign" or to refrain from doing so and to lead a "responsible campaign" instead. Assume that a single NGO's campaign helps mobilize the scarce resource of public attention (and, thus, provides access to additional funding) by exaggerating or misrepresenting the needs of its distant beneficiaries or by otherwise feeding "the spurious and mistaken beliefs" (Pincione and Tesón 2006, p. 4) of the general public. In contrast, assume that a responsible campaign would largely rely on "truth-sensitive" arguments (Pincione and Tesón 2006, p. 17) that display the best available evidence in academic discourse (or on a nuanced and balanced position that incorporates the wide panorama of available arguments) to promote the NGO's mission. ${ }^{10}$

The ordinal payoffs indicate how the strategy combinations are valued by each NGO individually. The number before the comma applies to NGO 1, the number after the comma to NGO 2 (Figure 2a).

Figure 2 about here

Assuming rational NGOs, this game can easily be solved: If NGO 2 leads a populist campaign, it is beneficial for NGO 1 to do the same because, otherwise, it would gain less or even no public attention, with adverse effect for its mission (and its prospects for funding). A comparison between Boxes III and IV shows $2>1$. However, if NGO 2 invests in responsible campaigns, NGO 1 is again better off refusing responsible conduct, because populist campaigns yield a comparative advantage in public attention over NGO 2-a comparison between Boxes I and II shows $3 \prec 4$. As the same logic holds for NGO 2, it becomes obvious

\footnotetext{
${ }^{10}$ When applied to fulfilling their mission in service delivery, the strategies for NGOs can be reconstructed as „mission-supporting service delivery“ and „mission-undermining service delivery.“
} 
that under these circumstances both NGOs find themselves under strong pressure to lead irresponsible campaigns. Yet the strategy combination that results in Box III (Nash equilibrium) is Pareto-inferior compared to Box I. Both NGOs are trapped in a situation of collective self-damage: leading irresponsible campaigns undermines the collective credibility and integrity-i.e. the "moral capital" (Crack 2013a, p. 813) or the "reputation" (Prakash and Gugerty 2010, 6-7) — of NGOs as a group in their efforts to advocate the interests of marginalized groups, peoples and issues. In addition, it is important to note that NGOs do not intend to achieve this equilibrium; it rather evolves as a non-intended consequence of intentional behavior. It is a systemic result.

A specific example of the NGO competition dilemma is what service delivery NGOs report on as defamation by peer organizations (Priller et al. 2012) or turf battles (Romzek et al. 2012). Again, the result of the competition dilemma ensues as a non-intended consequence of intentional behavior: What is intended as a prudent strategy to secure contractual relationships and funding turns out to be a substantive threat to the collective reputation of NGOs and their future capacity to collaborate in non-competitive issues. In the end, it's the intended beneficiaries who foot the bill.

It is important to bear in mind that in a many-sided dilemma, an individual selfcommitment can never solve the problem of collective self-damage. Starting from the status quo in Box III, a unilateral change of strategy by NGO 1 would lead to NGO 1's worst outcome: the payoff would decline from 2 to 1 (Box IV). Mutual betterment is only possible by shifting from Box III to Box I, which requires a collective self-commitment of both NGOs to simultaneously change strategies (Fig. 2b). A sanction, s, to punish populist campaigns will be effective if it is severe enough to make sure that $4-\mathrm{s}<3$ and that $2-\mathrm{s}<1$. Thus, only a collective commitment device that simultaneously binds all actors involved can overcome the symmetric logic of the "NGO competition dilemma." 
In principle, the competition dilemma can be solved either by NGO self-regulation initiatives or by state regulation using the enforcement power of nation-state governance (Gugerty 2010, 1089). Yet, the governance literature remains skeptical about governments to provide the effective and nonpartisan enforcement necessary to produce the collective good of regulation, e.g. in financial regulation. The literature reports on state ineffectiveness in regulation on a global level (Irvin 2005) and on the national level (i.e. the case of New Zealand, cf. Cordery 2013, p. 848) as well as on the problem of state cooptation (e.g. in the case of Russia, cf. Burger 2012, p. 87). As a consequence, the governance literature on nonprofit management embraces NGO self-regulation as a favorable solution, although it is only starting to analyze such collective action within the club-goods framework (Prakash and Gugerty 2010). In an effort to contribute to understanding the different institutional forms of NGO self-regulation, Gugerty (2010, table 1, p. 1091) differentiates between "national systems (i.e. classical collective good as substitute to state regulation), voluntary standard clubs (i.e. collective club goods) and voluntary codes of conduct."

((3)) The conceptual distinction between a one-sided and a social dilemma adds an important aspect to the governance literature on NGO accountability. Table 1 is a modification of Crack's (2011, p. 12) overview to describe the two waves of NGO Accountability, with first-wave accountability addressing donors and political authorities and second-wave reforms covering personnel, members, intended beneficiaries and peer organizations. In the real world, NGOs are embedded in a complex net of stakeholder relationships with specific and partly contradicting demands, which indicates that the stakeholder and the competition dilemma are not mutually exclusive but overlapping interaction problems.

As a general rule of thumb, table 1 indicates that one-sided social dilemmas are more prevalent in first-wave stakeholder relations and many-sided dilemmas much more probable 
in relation to second-wave stakeholders. In addition, when moving from left to right in Table 1, one-sided dilemma situations face a gradually decreasing sanction potential by secondwave stakeholders. This means that the increasing role of competitive pressure puts constraints on single NGOs to increase accountability by single individual efforts. To the extent that the "paradox of greater NGO accountability" (O’Dwyer and Unerman 2008, p. 1) is caused by competitive pressures to raise funds, and raising funds depends on media coverage and public awareness, it is unlikely that the underlying many-sided social dilemma will be solved on the organizational level of the individual NGO. This suggests that addressing governance reforms in NGO accountability relations to second-wave stakeholders (right side of Table 1) needs to rely much more on collective commitments than governance reforms in NGO accountability relations to first-wave stakeholders (left side of Table 1).

Table 1 about here

An interesting example of how self-regulation initiatives can help shaping a whole panorama of diverse accountability relationships is the INGO Accountability Charter (INGO Charter 2016). NGOs have established a wide range of organizational accountability mechanisms such as disclosure and reporting procedures that help overcome (one-sided) stakeholder dilemmas in various manifestations. From an ordonomic perspective, the INGO Charter is an attempt of large and influential international NGOs to improve the individual measures in all stakeholder relations, including first and second wave, by sectoral accountability standards, monitored by the INGO Charter's genuine procedures.

First wave: In relation to financial stakeholders (donors), NGOs may be tempted to use "exploitation" strategies by decreasing e.g. the quality of delivering services ex post of the contract, and use the spared resources to subsidize other activities (Cooley and Ron 2002). 
When raising funds from private donors, NGOs may be inclined to hide their actual agenda and trick potential donors about the how they intent to use donations (Prakash and Gugerty 2010). NGOs might also pretend meeting legal requirements to obtain advantages such as tax reductions without bearing the costs for legal compliance. In practice, financial and legal stakeholders possess a high sanctioning potential; they can (easily) withdraw funds or deny the legal status. This uneven distribution of power has prompted scholars to coin these relationships as "upward accountability" (Slim 2002), which means that exploitation strategies are only attractive in some rare cases of highly asymmetric distributed information. Providing reliable information in voluntary reporting and meeting legal requirements makes exploitation strategies even less attractive. The INGO Charter further supports these individual commitments of NGOs with an external review procedure that helps NGOs to signal credibility to financial and legal stakeholders more effectively (Prakash and Gugerty 2010).

Second wave: To a certain extent, the empirical success of upward accountability reforms in the first wave is reflected in complaints of both practitioners and scholars that NGOs have lost sight of less powerful stakeholders in "downward accountability," giving rise to the socalled "accountability paradox" (O’Dwyer and Unermann 2008). In ordonomic terms, NGO leadership might be tempted to use "concealing" strategies ("exploitation" in Fig. 1) to hide serious mistakes and misconduct in an effort to sustain member support and to acquire and retain a qualified and motivated staff ("support" in Fig. 1). In a similar way, NGOs may be inclined to set aside the interests of intended beneficiaries ("exploitation" in Fig. 1) to gain public support for funding campaigns (Slim 2002, p. 6). Such NGO strategies can easily backfire if scandals bring misbehavior or misrepresentation to light and lead to a decline of member and public support. Implementing downward accountability mechanisms such as organizational CHMs or stakeholder dialogues help increase the credibility of individual self- 
binding commitments to refrain from concealing and misrepresentation strategies and help save future member support and cooperation with intended beneficiaries, which again fosters organizational reputation.

Recently, there is a growing awareness of downward accountability within NGOs, which, according to Schmitz et al. (2012, p. 1188) can be seen as an important "normative shift." In practice, however, NGOs still struggle to be accountable to second-wave stakeholders. To address these challenges, the INGO Charter binds member NGOs to introduce CHMs within their organization which are monitored by an external review process. For example, Greenpeace International implemented CHMs in almost half of their national chapters and received over 8500 supporter complaints in 2014 in relation to advocacy positions (approx. 1000), fundraising methods (approx. 1500) and breaching core values (approx. 4000) (Greenpeace Accountability Report 2014). In addition to the organizational CHM, the INGO Charter installed a 'sectoral' CHM that allows complaints to be addressed directly to the Charter if supporters believe that their complaints have not been adequately addressed and responded to by the individual NGO's CHM. From an ordonomic perspective, the INGO charter's CHMs can thus not only be seen as a service for single NGOs to improve the credibility of their individual self-commitments toward financial stakeholders (first wave), but also toward members and intended beneficiaries (second wave). In particular, the sectoral CHM creates additional incentives for individual NGOs to credibly bind itself to the promise not to exploit its stakeholders, including intended beneficiaries. In contrast to Prakash and Gugerty (2010), our rational-choice approach is capable of reconstructing and analyzing second-wave accountability mechanisms because it uses on open concept of utility.

Of course, we fully acknowledge the limited applicability of the stakeholder dilemma as heuristic to foster accountability to second-wave stakeholders, in particular when competitive processes create dysfunctional incentives for NGOs. From our ordonomic perspective, the 
INGO Charter can also be seen as a (potential) means to address a wider range of collective challenges including several manifestations of the competition dilemma. Seen in this light, peer accountability mechanisms are a form of collective self-binding commitments to a variety of accountability standards that are monitored by an external review process. By doing so, NGOs collectively infuse order (Williamson 2009; p. 456) to a formerly unregulated space and generate mutual gains for themselves and their stakeholders. But competition dilemmas are not limited to advocacy issues, they also appear in service delivery. For example, in specific contexts of institutionalized corruption (Fowler 2013, p. 21), NGO staff members might be tempted to apply corruptive practices when competing with other NGOs for projects with local authorities. Negative reputational effects for donors as well as for intended beneficiaries are the likely consequence. The INGO Charter can be seen as an attempt to create a collective self-binding commitment to implement of whistle-blowing systems on a sector-wide basis. Relying on review procedures and sectoral CHMs, the INGO Charter would be able to identify and sanction those organizations that do not comply with anticorruption standards, mainly through peer disapproval and loss of membership status. While donation and funding are surely the most obvious levels of competition among NGOs, the INGO Charter also raises sectoral standards with respect to "Ethical Fundraising" (INGO Charter 2016) that redlines effective, but morally controversial fundraising techniques (Manzo 2008). In relation to intended beneficiaries, the INGO Charter's principle 'Responsible Advocacy' sets standards how to generate responsible and exit irresponsible advocacy positions, which again can be seen as a solution to the competition dilemma of responsible campaigning. The current difficulties of NGOs to address the collective challenges of public accountability (Lang 2013) again highlight the need for a rational-choice approach capable of reconstructing and analyzing the underlying interaction problems and generating ideas to overcome collective self-damage. 


\section{How to Move Forward: Implications for a "Third Wave" of NGO Accountability Reforms}

This paper is intended to take the literature forward in developing a comprehensive rationalchoice-based governance approach of NGO behavior that paves the way for adequate reform proposals. We believe that our framework adds value to the literature because it facilitates fresh thinking about both new and established mechanisms to improve NGO accountability. In particular, we believe our approach helpful in theorizing about what Crack (2013a, p. 12) calls a "third wave of reforms to strengthen the institutionalization of dialogic and peer accountability," i.e. the implementation of (stakeholder) dialogues to empower 'intended' beneficiaries. This is viewed in the literature as an extremely difficult challenge, and observers remain skeptical about its potential of implementation due to high opportunity costs and a lack of skills.

The rational-choice perspective developed in this paper helps understand better the working properties of the first two reform waves and also to identify the key drivers of future reforms. In general, first wave governance reforms have primarily addressed principal-agent problems in one-sided social dilemma structures between NGOs and donors/legal authorities. Though relatively easy to implement and useful to establish trustful relationships with donors and legal authorities, the literature highlights that these reforms may have the additional adverse effect to dilute NGO efforts from staying accountable to members/personnel, peers and intended beneficiaries - a tendency that prompted second wave governance reforms. Our framework highlights that the biggest challenge of second wave reforms is NGO accountability towards intended beneficiaries, with different consequences on three different levels:

(i) NGO accountability toward intended beneficiaries can be reconstructed as a one-sided dilemma structure ("stakeholder dilemma") if stakeholders are (en)able(d) to articulate 
powerful feedback, the impact of which would be crucial for an individual NGO's reputation. For example, Amnesty International was heavily criticized in public discussions for adopting a policy of decriminalization of prostitution to protect the human rights of sex workers. In responding to this criticism, AI referred to a profound research and consultation process, which included various discussions with a wide range of stakeholders and an opinion survey among more than two hundred sex workers (Amnesty International 2015b). According to our ordonomic interpretation, AI was able to withstand strong public opposition because they invested (heavily) into an individual self-commitment to stay accountable, i.e. to speak 'responsibly' on behalf of their 'intended' beneficiaries. Yet this self-commitment is only possible because sex workers could easily object to AI's openly declared positions, which would do serious harm to AI's reputation as a 'true' advocate of their interests.

(ii) AI's "involvement of affected stakeholder groups" is considered a best practice example by the INGO Accountability Charter (2015) and surely deserves commendation. Yet, this formal recognition of AI's performance also indicates that effective dialogic accountability mechanisms are still rare. Our framework can show why: As Prakash and Gugerty (2010) point out, accountability to donors is not necessarily separated from the accountability to beneficiaries and accountability to donors can partly substitute accountability to beneficiaries. By the same token, 'NGO accountability to intended beneficiaries' is not necessarily separated from 'NGO accountability to peers,' and accountability to peers can substitute accountability to beneficiaries. The transition from beneficiaries to peers is a promising avenue due to the overlapping interests among both groups and the characteristics that most NGO peers share. First, intended beneficiaries and NGO peers have a shared interest in sector-wide responsible advocacy: intended beneficiaries with regard to the effectiveness of proposed policies by their advocates and NGO peers with regard to safeguarding their collective reputation and identity as promoters of the common 
good. Second, NGO peers have the expertise to evaluate the focal NGO's performance, and third, NGO peers have access to relevant information on potential free-rider activities due to increasing network communication among NGO peers (Romzek et al. 2012).

However, it seems that NGO self-regulation initiatives still struggle to generate sufficient sanction potential or additional benefits to "solve issues of compliance, implementation and enforcement that follow initial stages of standard setting" (Sidel 2010, p. 15). Recent research indicates that even those initiatives with strong external review procedures and sectoral CHMs face collective action problems. As an example, a study by the INGO Charter assessing the accountability performance of 40 leading international CSOs [including 25 member organizations] shows that "many CSOs haven't formulated and systemised a clearance process/fact check" (INGO Charter 2016b, p. 11), although all member organizations committed themselves to the Principle of Responsible Advocacy (INGO Charter 2016a). In addition, many member organizations are shown to miss a fully functioning CHM, which is the basic requirement for membership in the INGO Charter (INGO Charter 2016b, p. 10). Of course, on this basis it seems easy to criticize self-regulation initiatives for their lack of effectiveness in terms of compliance to committed standards. Yet, as we do, one could also interpret this self-exposure of serious accountability shortcomings as a signal to external stakeholders that the INGO Charter takes its commitments seriously and that member organizations need to show significant progress in the future.

Thus, the greatest challenges of second wave governance reforms culminates in establishing sectoral standards that address the competition dilemma in NGO advocacy. Though numerous voluntary regional and international initiatives have created accountability standards for the whole NGO sector (Hammer et al. 2010, p. 4-5), some most of them lack effective governance mechanism to identify and sanction non-compliance (Sidel 2010). One reason is that competing self-regulation initiatives may be tempted to lower their 
accountability standards in order to attract new members. Preventing race-to-the-bottom dynamics on the level of standards is an extraordinary challenge that requires mutual acknowledge and partly harmonization of competing accountability frameworks to establish comprehensive sectoral standards.

(iii) A way to facilitate NGO sector-wide solutions can be seen in bi-sectoral initiatives, which could help enhance the effectiveness of collective self-regulation of NGOs. Though there are examples of bi-sectoral partnerships between the private sector and nation-state authorities or even supranational authorities (e.g. United Nations Global Compact, Forrest Stewardship Council, Marine Stewardship Council), incorporating state authorities in NGO sector-wide accountability standards does not come without a risk. Thus, it might be much easier to think about bi-sectoral initiatives between companies and NGOs as a balanced partnership of equals. In fact, competition to attract public attention is not limited to the NGO sector, but also involves the for-profit sector. As a result, it might be worth discussing a partnership such as a "global responsible communication standard"11. For sure, the development of such a standard would be an extraordinary challenge due to conflicting interests and the potentially large number of participants. Yet, it could refer to and, in part, also build upon already established accountability standards within the NGO sector. For example, the INGO Accountability Charter (2016a) has a "responsible advocacy" standard that states: "[b]eing responsible in our public criticism, ensuring it amounts to fair public comment and giving a right of reply."

Crack's (2013a) two-wave framework of accountability reforms reproduces the broad and overall chronological order of governance reforms. Each reform wave builds on the former, with the later wave incorporating the former. However, our analysis draws particular attention

\footnotetext{
${ }^{11}$ We owe the idea of a "global responsible communication standard" to Kernaghan Webb. He outlined this concept as a way of fostering trustful and fair dialogues among actors of different sectors, in particular between business firms and civil society.
} 
to a second dimension that works in the opposite direction. In addition to the chronological dimension, there are also potentially positive feedback effects, which means that higher wave reforms can also support the effectiveness of lower wave reforms to solve accountability challenges. While there has been a great deal of discussion about the potential of NGO accountability to foster organizational learning (Slim 2002, Ebrahim 2005), the 'competition dilemma' underlines the need for a learning process to mitigate the adverse effects caused by unregulated competition. "Third" wave reform initiatives (such as discussing about and implementing a bi-sectoral initiative) can facilitate NGO sector-wide initiatives to establish higher communication standards (Will and Pies 2016). In addition, developing an effective regulatory regime for peer accountability to solve the competition dilemma of NGO advocacy can be seen as a "sectoral learning process" that translates into positive incentives to solve the stakeholder dilemma via accountability mechanism such as the CHM or stakeholder dialogues.

In sum, our ordonomic social dilemma analysis provides an 'alternative' reconstruction of relationships in NGO accountability. On the ideational level, this approach does not rely on pure good will of NGOs. Its unique feature is to incorporate value-based and organizational interests of NGOs, including monetary and non-monetary, in its analysis. From a pragmatic perspective, thus, the proposed reforms promote a crystal clear win-win orientation which should help NGOs to effectively engage in self-regulation. As an illustration, Prakash and Gugerty's (2010, p. 4 and 10) use of rational-choice theory leads them to view self-regulation clubs primarily as a means to satisfy the needs of important financial stakeholder such as donors. In criticizing this perspective, Deloffre (2010, p. 191) points out that "humanitarian NGOs designed accountability clubs in order to meet their perceived moral duty, not in response to agency dilemmas." In fact, according to our framework, these views do not contradict each other, but both are deserving of merit in their own right. The ordonomic use of rational-choice theory suggests an ideational perspective that both NGO goals-donor 
interests and the moral mission — can be assigned to different levels in a multiple means-end scheme. In analogy to AI's commitment to waive financial resources of governments or political parties, accountability clubs can be interpreted as a means to serve the interim end of satisfying the needs of donors (Prakash and Gugerty 2010), which in turn serves as a means to achieve the final end of living up to their moral mission (Deloffre 2010).

\section{Conclusion and Further Research}

Fostering NGO accountability is a complex issue that includes not only practical but also conceptual challenges with enormous social relevance. To support this endeavor, we have developed a comprehensive rational-choice based governance framework to interpret the stakeholder relationships of NGOs as interaction problems and we identify two archetypical dilemma structures: the "stakeholder dilemma" between the NGO and a single accountability holder as a one-sided social dilemma and the "competition dilemma" among rival NGOs as many-sided social dilemma. We also believe that our framework supports NGOs and their managers to put the issue of competition among NGOs high on the agenda of their networks, cooperation and alliances and to design and implement (more) effective forms of selfregulation.

In terms of future research, our analysis suggests at least three ways for future research efforts: First, our analysis shows that NGOs face difficulties addressing both the stakeholder and the competition dilemma. A potential remedy can be seen in integrating credible third parties as facilitators of individual and collective self-binding commitments, which can be seen as services for individual and collective forms of self-commitment (cf. Pies et al. 2009, p. 388 et seq.) For example, the problem of NGOs to provide credible knowledge about the effects of promoted policies to intended beneficiaries can be mitigated by partnering with scientific bodies (Copestake 2014). Cooperating with scientists provides an opportunity for high quality evaluations and policy analysis if these academic bodies face adequate incentives 
to maintain a strong reputation of academic integrity and respectability. While such external evaluation processes represent a prudent NGO strategy vis-á-vis a one-sided social dilemma with well-intentioned funders, an individual NGO might face a strong disincentive to engage in such practices in a competitive funding environment. However, seen from the collective perspective of all NGOs affected by negative reputation, there is a strong collective interest of the group of NGOs to raise sectoral standards by appropriate governance mechanisms, even if these efforts are only supported by single but large funders and, thus, fall short of providing a complete, sanction-based NGO self-regulation in the first place.

Second, long-term studies on the results of industry self-regulation in the corporate sector underline the need for a better understanding of effective governance mechanisms that guarantee high (moral) standards of organizational behavior. Most recently, multi-stakeholder initiatives (MSI) such as the Forest Stewardship Council (FSC) have been heavily criticized for their lack of effectiveness, low-quality standards and lack of stakeholder support (Moog et al. 2015). Though we suggest thinking in more detail about the potential of bi- and multisectoral initiatives to enhance NGO accountability, their critical working propertiesincluding the self-perception of NGOs as pure promoters of the common good-remain an important question for further research.

Third, we have treated NGOs as collective, "single unitarian" moral actors throughout this paper. On the one hand, this is a reasonable methodological decision to reduce complexity insofar as the moral misconduct of a single NGO personnel or volunteer can easily and directly translate into reputational damages for the focal NGO. To address the negative actual and future consequences, the NGO then has no other choice but to react as a collective actor using organizational counter measures. On the other hand, although not in the immediate focus of this present paper, our rational-choice-based governance approach can be equally applied to intra-organizational relationships within a particular NGO. For example, moral 
misconduct in interactions between different "hierarchical" levels can be analyzed using a one-sided social dilemma. Focusing on e.g. the interaction between NGO managers and NGO employees could study the potential for managers to exploit employees or vice versa, which could result in a morally undesired situation such as withholding important information about specific NGO activities that can unintentionally lead to misrepresenting interests or silencing voices of intended beneficiaries. Moral misconduct could also take place among equals, i.e. among NGO volunteers on the same level within the NGO "hierarchy." Such a situation could be analyzed with a many-sided social dilemma, and it could highlight how moral standards can easily erode within a team if a moral leadership is absent that places high priority on supporting moral standards with adequate intra-organizational governance arrangements.

\section{References}

AbouAssi, K. (2012). Hands in the pockets of mercurial donors: NGO response to shifting funding priorities. Nonprofit and Voluntary Sector Quarterly, 42(3), 584-602.

Amnesty International (2015a). Our finance. Online available: http://www.amnesty.org.uk/ourfinances\#.VaY93GOHqPk $(15.07 .2015)$

Amnesty International (2015b). Q\&A: Policy to protect the human rights of sex workers. Online available at: https://www.amnesty.org/en/qa-policy-to-protect-the-human-rights-of-sex-workers (28.10.2015)

Axelrod, R. (1980). Effective choice in the prisoner's dilemma. The Journal of Conflict Resolution, 24(1), 3-25.

Becker, G. S. (1992). Nobel lecture. The economic way of looking at behavior. The Journal of Political Economy, 101(3), 385-409.

Beckmann, M., Hielscher, S. and Pies, I. (2014). Commitment strategies for sustainability: How business firms can transform trade-offs into win-win outcomes. Business Strategy and the Environment, 23 (1), 18-37. 
Benjamin, L. M. (2008). Account space: How accountability requirements shape nonprofit practice. Nonprofit and Voluntary Sector Quarterly, 37(2), 201-223.

Bowles, S. (2004). Microeconomics. Behavior, institutions and evolution, Princeton University Press, New York, Oxford and Princeton.

Buchanan, J. M. (1965). An economic theory of clubs. Economica, 32(125), 1-14.

Buchanan, J. M. (1987). Constitutional economics. In Eatwell, J. (eds), The New Palgrave Dictionary of Economics, 1, 585-88, Macmillan, London.

Buchanan, J. M. (1990). The domain of constitutional economics. Constitutional Political Economy, 1(1), 1-18.

Burger, R. (2012). Reconsidering the case for enhancing accountability via regulation. VOLUNTAS: International Journal of Voluntary and Nonprofit Organizations, 24(1), 85-108.

Brown, L. D. (2008). Creating credibility: Legitimacy and accountability for transnational civil society. Kumarian Press.

Brown, D. L. and Moore, M. H. (2001). Symposium: New roles and challenges for NGOs. Accountability, strategy, and international nongovernmental organizations. Nonprofit and Voluntary Sector Quarterly, 30(1), $569-587$

Brown, D. L. and Kalegaonkar, A. (2002). Support organizations and the evolution of the NGO sector. Nonprofit and Voluntary Sector Quarterly, 31(2), 231-258.

Brown, D.L.; Ebrahim, A. and Srilatha B. (2012). Governing International Advocacy NGOs. In: World Development 40(6), 1198-1108.

Cavill, S. und Sohail, M. (2007). Increasing strategic accountability: A framework for international NGOs. Development in Practice 17(2), 231-248.

Chen, K. K. (2012): Storytelling. An informal mechanism of accountability for voluntary organizations. Nonprofit and Voluntary Sector Quarterly, 42(5), 902-922.

Cooley, A., and Ron, J. (2002). The NGO scramble: Organizational insecurity and the political economy of transnational action. International Security, 27(1), 5-39.

Copestake, J. (2014). Credible impact evaluation in complex contexts: Confirmatory and exploratory approaches. Evaluation, 20(4), 412-427. 
Cordery, J. C. and Baskerville, R. F. (2010). Charity transgressions, trust and accountability. VOLUNTAS: International Journal of Voluntary and Nonprofit Organizations, 22(2), 197-213.

Cordery, J. C. (2013). Regulating small and medium charities: Does it improve transparency and accountability?. VOLUNTAS: International Journal of Voluntary and Nonprofit Organizations, 24(13), 831-851.

Crack, A. M. (2013a). Language, listening and learning: Critically reflective accountability for INGOs. International Review of Administrative Sciences 79(4), 809-828.

Crack, A. M. (2013b). INGO accountability deficits: The imperatives for further reform. Globalizations 10(2), 293-308.

Crack, A. M. (2014). Reversing the telescope: Evaluating NGO peer regulation initiatives. Journal of International Development, online first, DOI: 10.1002/jid.3010.

Dochas; Irish Association of Non-Governmental Development Organisations: About the Code. Code of Conduct on Images and Messages: Online available under: http://www.dochas.ie/about-the-code (20.06.2016)

Deloffre, M. Z. (2010). NGO accountability clubs in the humanitarian sector: Social dimensions of club emergence and design. In Prakash, A. and Gugerty, M. K. (eds), Voluntary Regulation of NGOs and Nonprofits: An Accountability Club Framework, 169-200, Cambridge University Press. New York.

Ebrahim, A. (2002). Information struggles: The role of information in the reproduction of NGO-funder relationships. Nonprofit and Voluntary Sector Quarterly, 31(1), 84-114.

Ebrahim, A. (2003). Accountability in practice: Mechanisms for NGOs. World Development 31(5), 813-829.

Ebrahim, A. (2005). Accountability myopia: Losing sight of organizational learning. Nonprofit and Voluntary Sector Quarterly, 34(1), 56-87.

Edelman (2015). Edelman trust barometer executive summary. Available online at: http://www.edelman.com/insights/intellectual-property/2015-edelman-trust-barometer/trust-and-innovationedelman-trust-barometer/executive-summary/ (05.10.2015)

Gibelman, M. and Gelman, S. R. (2001). Very public scandals: Nongovernmental organizations in trouble. VOLUNTAS: International Journal of Voluntary and Nonprofit Organizations, 12(1), 49-66.

Greenle, J., Fischer, M., Gordon, T. and Keating, E. (2007). An investigation of fraud in nonprofit organizations: occurrences and deterrents. Nonprofit and Voluntary Sector Quarterly, 36(4), 676-694. 
Hammer, M., Rooney, C. and Shana, W. (2010). Addressing accountability in NGO advocacy. Practice, principles and prospects of self-regulation, Briefing Paper 125, One World Trust. Online available at: http://www.coddeconduitaong.ro/resurse/Self_regulation_of_advocacy_among_NGOs.pdf (01.11 .2014).

Hardin, G. (1968). The tragedy of the commons. science, 162 (3859), 1243-1248.

Heckman, James J. (2015): Gary Becker: Model Economic Scientist, IZA Discussion Paper No. 8827, February 2015, Online available at: http://ftp.iza.org/dp8827.pdf.

Hielscher, S., \& Pies, I. (2016). Emergent Social Dilemmas in Modern Society: An Institutional Economics' Perspective. Syst. Res. Behav. Sci, 3.

Hortsch, D. (2010). The paradox of partnership. Amnesty International, responsible advocacy, and NGO accountability, Columbia Human Right Law Review, 42, 119-155.

Hug, N. and Jäger, U. P. (2014). Resource-based accountability: A case study on multiple accountability relations in an economic development nonprofit. VOLUNTAS: International Journal of Voluntary and Nonprofit Organizations, 25(3), 772-796.

INGO Accountability Charter (2015). Good practice. Available online at: http://www.ingoaccountabilitycharter.org/good-practice/ (28.10.2015)

INGO Accountability Charter (2016a). Home. The INGO Accountability Charter. Available online at: http://www.ingoaccountabilitycharter.org/ (01.09.2016)

INGO Accountability Charter (2016b). Excellence of CSO in Accountability. Available online at: http://www.ingoaccountabilitycharter.org/wpcms/wp-content/uploads/direct-impact-group-@ -INGO-

Accountability-Charter-AGM.pdf (01.09.2016)

Irvin, R. A. (2005). State regulation of nonprofit organizations: Accountability regardless of outcome. Nonprofit and Voluntary Sector Quarterly, 34(2) 161-178.

Jepson, P. (2005). Governance and accountability of environmental NGOs. Environmental Science \& Policy, $8(5), 515-524$.

Jensen, M. C. and Meckling, W. H. (1976). Theory of the firm: Managerial behavior, agency costs and ownership structure. Journal of financial economics, 3(4), 305-360.

Kane, J. (2001). The politics of moral capital. Cambridge University Press. 
Kilby, P. (2006). Accountability for empowerment: Dilemmas facing non-governmental organizations. World Development, 34, 951-963.

Kreps, D. M. (1990). Corporate culture and economic theory. Perspectives on positive political economy. Cambridge University Press. Cambridge.

Lang, S. (2013). NGOs, Civil Society, and the Public Sphere. Cambridge University Press. Cambridge.

Lister, S. (2003). NGO legitimacy technical issue or social construct? Critique of Anthropology 23(2): 175-192.

Ljubownikow, S., Crotty, J. and Rodgers, P. W. (2013). The state and civil society in post-soviet russia: The development of a russian-style civil society. Progress in Development Studies, 13(2), 153-166.

Manzo, K. (2008). Imaging humanitarianism: NGO identity and the iconography of childhood. Antipode, 40(4), 632-657.

Murtaza, N. (2011). Putting the lasts first: The case for community-focused and peer-managed NGO accountability mechanism. VOLUNTAS: International Journal of Voluntary and Nonprofit Organizations, 23(1), 109-125.

O’Dwyer, B., and Unerman. J. (2008). The Paradox of greater NGO accountability: A case study of Amnesty Ireland. Accounting, Organizations and Society, 33(7-8), 801-824.

Omona, J. and Mukuye. R. (2013). Problems of credibility of NGOs in uganda: Implications of theory and practice. VOLUNTAS: International Journal of Voluntary and Nonprofit Organizations, 24(2), 311-334.

Phillips, S. D. (2012). Canadian leapfrog: From regulating charitable fundraising to co-regulating good governance. VOLUNTAS: International Journal of Voluntary and Nonprofit Organizations, 23(3), 808-829.

Pies, I. (2009). Das ordonomische Forschungsprogramm. Diskussionspapier Nr. 2009-7, Halle-Wittenberg.

Pies, I., Hielscher, S., \& Beckmann, M. (2009). Moral commitments and the societal role of business: An ordonomic approach to corporate citizenship. Business Ethics Quarterly, 19(03), 375-401.

Pies, I, Beckmann, M. and Hielscher, S. (2010). Social value creation, management competencies, and global corporate citizenship - An ordonomic approach to business ethics in the age of globalization. Journal of Business Ethics, 94(2), 265-278.

Pies, I.; Beckmann, M. and Hielscher, S. (2014). The political role of the business firm: An ordonomic reconceptualization of an aristotelian idea. Business \& Society, 53(2), 226-259. 
Pincione, G. and Tesón, F. R. (2006). Rational choice and democratic deliberation: A theory of discourse failure. Cambridge University Press. Cambridge.

Martens, K. (2002). Mission impossible? Defining nongovernmental organizations. Voluntas: International Journal of Voluntary and Nonprofit Organizations, 13(3), 271-285.

Minkoff, D.C. and Powell, W.W. (2006). Nonprofit Mission: Constancy, Responsiveness, or Deflection? In: Powell, D.D. and Steinberg, W. (Ed.): The Nonprofit Sector. A Research Handbook. Yale University Press, New Haven, London.

Moog, S., Spicer, A., \& Böhm, S. (2015). The politics of multi-stakeholder initiatives: The crisis of the Forest Stewardship Council. Journal of Business Ethics, 128(3), 469-493.

Prakash, A and Gugerty, M. K. (2010). Trust but verify? Voluntary regulation programs in the non profit sector. Regulation and Governance, 4(1), 22-47.

Prakash, A. and Potoski, M. (2007). Collective action through voluntary environmental programs: A club theory perspective. The Policy Studies Journal, 35(4), 773-792.

Priller, R.; Alscher, M.; Droß, P.; Paul, F.; Poldrack, C.; Schmeißer, C. and Waitkus, N. (2012). Dritte-SektorOrganisationen heute: Eigene Ansprüche und ökonomische Herausforderungen. Ergebnisse einer Organisationsbefragung. Discussion Paper SP IV 2012 - 402, Berlin: WZB, www.wzb.eu/org2011.

Romzek, B. S.; LeRoux, K. and Blackmar, J. M. (2012). A Preliminary Th eory of Informal Accountability among Network Organizational Actors. Public Administration Review 72(3), 442-453.

Salamon, L. and Anheier, H. K. (1992). In search of the nonprofit sector II: The problem of classification. Voluntas 3(3), 267-309.

Saxton, G. D. and Guo, C. (2011). Accountability online: Understanding the web-based accountability practices of nonprofit organizations. Nonprofit and Voluntary Sector Quarterly, 40(2), 270-295.

Schmitz, H. P., Raggo, P. and Vijfeijken, T. B. (2012). Accountability of transnational NGOs: Aspirations vs. practice. Nonprofit and Voluntary Sector Quarterly, 41(6), 1176-1194.

Sen, A. (1977). Rational fools: A critique of the behavioral foundations of economic theory. Philosophy \& Public Affairs, 6(4), 317-344.

Sidel, M. (2010). The promise and limits of collective action for nonprofit self-regulation: Evidence from Asia. Nonprofit and Voluntary Sector Quarterly 39(6), 1039-1056. 
Slim, H (2002). By what authority? The legitimacy and accountability of non-governmental organizations. The International Council on Human Rights Policy, Working Paper. Available at: www.ichrp.org/paper_files/119_w_02.doc.

Sloan, M. F. (2009). The effects of nonprofit accountability ratings on donor behavior. Nonprofit and Voluntary Sector Quarterly, 38(2), 220-236.

Szper, R. and A. Prakash (2011). Charity watchdogs and the limits of information-based regulation. VOLUNTAS: International Journal of Voluntary and Nonprofit Organizations, 22(1), 112-141.

Swinnen, J. (2011). The right price of food. Development Policy Review, 29(6), 667-688.

Swinnen, J., Squicciarini, P. and Vandemoortele, T. (2011). The food crisis, mass media and the political economy of policy analysis and communication. European Review of Agricultural Economics 38(3), 409426.

Vakil, A. C. (1997). Confronting the Classification Problem. Toward a Taxonomy of NGOs. World Development, 25(12), 2057-2070.

Valentinov, V., \& Chatalova, L. (2014). Institutional economics and social dilemmas: a systems theory perspective. Systems Research and Behavioral Science.

Valentinov, V., Hielscher, S., and Pies, I. (2013). The meaning of nonprofit advocacy: An ordonomic perspective, The Social Science Journal, 50(3), 367-373.

Valentinov, V., Hielscher, S., and Pies, I. (2015). Nonprofit organizations, institutional economics, and systems thinking, paper accepted for publication in Economic Systems.

Webb, K. (2016, forthcoming). Overcoming Discourse Failure: Exploring the Feasibility and Desirability of a Global Responsible Communication Standard.

Will, M. G., \& Pies, I. Discourse Failures and the NGO Sector: How Campaigning Can Undermine Advocacy. VOLUNTAS: International Journal of Voluntary and Nonprofit Organizations, 1-32.

Williams, A. P., and Taylor. J. A. (2013). Resolving accountability ambiguity in nonprofit organizations. VOLUNTAS: International Journal of Voluntary and Nonprofit Organizations, 24(3), 559-580.

Williamson, O. E. (1985). The economic institutions of capitalism. Free Press. New York.

Williamson, O. E. (2009). Transaction cost economics: The Natural Progression. Nobel Prize Lecture, Sweden, Oslo. 
XXX (2015). NGO Credibility As Private or Public Good? A Governance Perspective on How to Improve NGO

Advocacy in Public Discourse. Working Paper, unpublished manuscript.

Figures and Tables

Figure 1: The NGO Accountability Dilemma

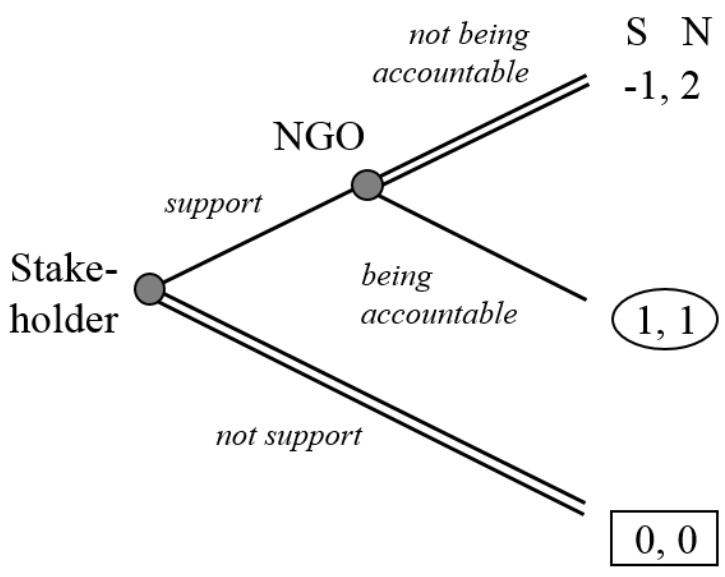

(a)

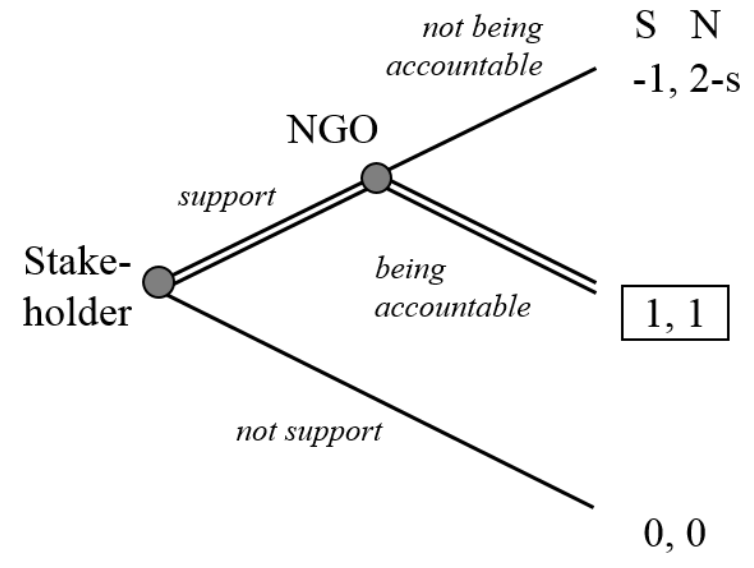

(b)

Figure 2: The NGO Competition Dilemma

Campaigning: ...?

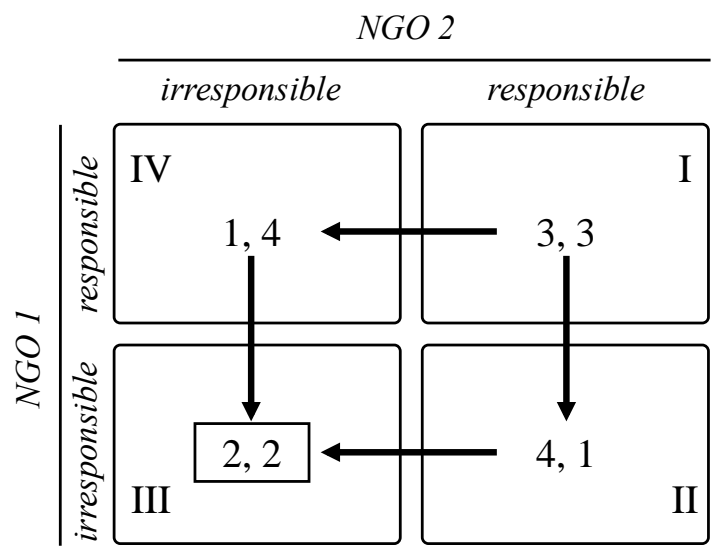

(a)

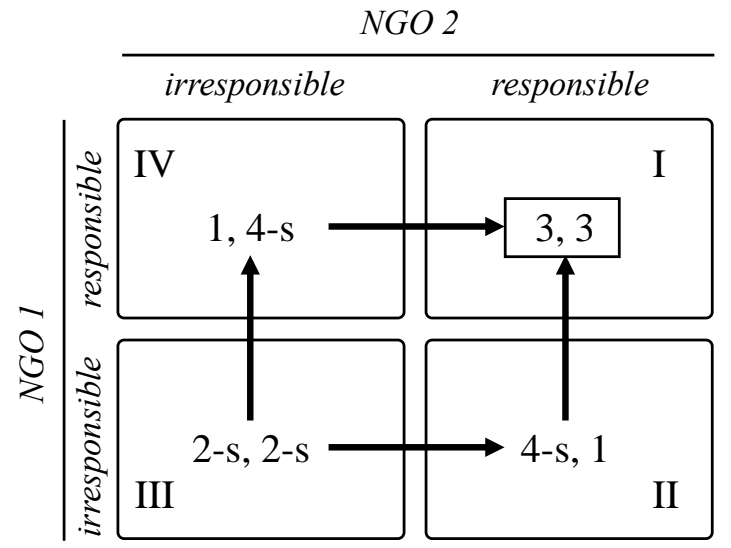

(b) 
Table 1: The Two Waves of NGO Accountabiltiy related to two Forms of Social Dilemmas

\begin{tabular}{|c|c|c|c|c|c|}
\hline \multirow[b]{2}{*}{ Form of Accountability } & \multicolumn{2}{|c|}{$\begin{array}{l}\text { First Wave: } \\
\text { Accountability of Good Governance }\end{array}$} & \multicolumn{3}{|c|}{$\begin{array}{c}\text { Second Wave: } \\
\text { Accountability to Mission }\end{array}$} \\
\hline & Fiscal & Legal & Dialogic (intern) & Dialogic (extern) & Peer \\
\hline Accountability Holder & Donors & Political Authority & $\begin{array}{l}\text { Personnel, } \\
\text { Members }\end{array}$ & $\begin{array}{c}\text { Intended } \\
\text { Benificiaries }\end{array}$ & NGO Peers \\
\hline $\begin{array}{c}\text { Example of } \\
\text { Governance Mechanism }\end{array}$ & Annual report & $\begin{array}{l}\text { UK Charity } \\
\text { Commission }\end{array}$ & $\begin{array}{c}\text { Policy } \\
\text { consultations, } \\
\text { AGMs, Board } \\
\text { elections, CHM }\end{array}$ & $\begin{array}{c}\text { Social audit, } \\
\text { Actions Aid ALPS }\end{array}$ & $\begin{array}{c}\text { INGO } \\
\text { Accountability } \\
\text { Charter, HAP }\end{array}$ \\
\hline Main Sanction & $\begin{array}{l}\text { Withdrawal of } \\
\text { funds }\end{array}$ & $\begin{array}{l}\text { Loss } / \text { Denial of } \\
\text { registered status }\end{array}$ & $\begin{array}{l}\text { Demoralized } \\
\text { staff/volunteers, } \\
\text { Cancelation of } \\
\text { membership }\end{array}$ & $\begin{array}{l}\text { Withdrawal of } \\
\text { cooperation of } \\
\text { beneficiaries, } \\
\text { damaged reputation }\end{array}$ & $\begin{array}{c}\text { Peer disapproval, } \\
\text { loss of } \\
\text { membership } \\
\text { status }\end{array}$ \\
\hline $\begin{array}{c}\text { Level of } \\
\text { Institutionalization }\end{array}$ & Strong & Strong & Weak & Weak & Weak \\
\hline $\begin{array}{l}\text { Form of Social } \\
\text { Dilemma }\end{array}$ & $\begin{array}{l}\text { Primarily one- } \\
\text { sided Social } \\
\text { Dilemma }\end{array}$ & $\begin{array}{l}\text { Primarily One- } \\
\text { Sided Social } \\
\text { Dilemma }\end{array}$ & $\begin{array}{l}\text { Primarily Many- } \\
\text { Sided Social } \\
\text { Dilemma }\end{array}$ & $\begin{array}{l}\text { Primarily Man- } \\
\text { Sided Social } \\
\text { Dilemma }\end{array}$ & $\begin{array}{l}\text { Many-Sided } \\
\text { Social Dilemma }\end{array}$ \\
\hline
\end{tabular}

